\title{
Las obras musicales religiosas de Vicente Bianchi Alarcón ${ }^{1}$
}

\section{Religious musical Works by Vicente Bianchi Alarcón}

\author{
por \\ Cristián Guerra Rojas \\ Departamento de Música, Facultad de Artes, Universidad de Chile, Chile \\ cguerrar@uchile.cl
}

\begin{abstract}
En este artículo se expone un primer abordaje a la producción musical religiosa del compositor chileno Vicente Bianchi Alarcón (n. 1920), Premio Nacional de Artes Musicales 2016 de Chile. Se presentan antecedentes para comprender esta obra, en la que se pueden distinguir dos grandes rubros: música navideña y música litúrgica. A continuación se hace una presentación general de las obras pertenecientes a cada uno de estos rubros, luego una consideración de aspectos estilísticos significativos que se observan en este corpus. Finalmente se plantean perspectivas desde puntos de vista musicales, teológicos y socioestéticos respecto de esta producción.

Palabras clave: Vicente Bianchi, música religiosa, música navideña, música litúrgica, Concilio Vaticano II.

A first approach to religious musical output of Chilean composer Vicente Bianchi Alarcon (b. 1920), National Prize of Musical Arts 2016 in Chile, is exposed in this paper. A background to understand this output is presented as two great items can be distinguished: Christmas music and liturgical music. Then works from each of these items are presented and later an approach to meaningful stylistic features that can be observed in this corpus. Finally some prospects from musical, theological and socioaesthetic viewpoints are proposed about this output.

Keywords: Vicente Bianchi, religious music, Christmas music, liturgical music, 2nd Vatican Council.
\end{abstract}

\section{ANTECEDENTES}

Una parte significativa de la producción creativa del compositor chileno Vicente Bianchi Alarcón (n. 1920), Premio Nacional de Artes Musicales 2016, concierne al ámbito religioso. Aunque nacido en el seno de una familia católica, no fue un niño particularmente religioso, pero con los años y antes de las resoluciones del

1 Este trabajo forma parte del Proyecto Fondecyt (Fondo de Ciencia y Tecnología) N ${ }^{\circ} 1160102$, "La institucionalización de la modernidad de la música clásica como práctica social entre 1928 y 1973 en el marco de la Universidad de Chile”, cuyo investigador responsable es el Dr. Luis Merino Montero y yo participo como coinvestigador. 
Concilio Vaticano II acerca de música y liturgia, desarrolló una inquietud por crear obras que acercaran el ritual católico a la comunidad de feligreses ${ }^{2}$.

Para comprender el aporte que este compositor ha hecho en este campo se debe considerar en primer lugar que la formación de oficio de Bianchi como compositor, arreglista y director tuvo lugar en la radio ${ }^{3}$. Bianchi no fue un músico formado en la iglesia sino en la radio, en el mundo de las músicas populares urbanas, por tanto sus principales referencias al incursionar en el ámbito musical religioso provenían de ese estrato. Y en segundo lugar, si bien las primeras piezas y proyectos musicales que Bianchi concibió en este ámbito son anteriores a la realización del Concilio Vaticano II y sus resoluciones, el marco propiciado por este evento fue el que permitió al compositor desarrollar sus propuestas. $\mathrm{Al}$ respecto, si bien la composición de varias de sus piezas musicales religiosas fue motivada a partir de un encargo institucional o solicitud personal de terceros, la mayor parte de estas piezas surgió por iniciativa propia del compositor.

Con estos antecedentes fundamentales para comprender la obra musical religiosa de Bianchi, podemos enfocarnos en ella a partir de una clasificación preliminar que toma en cuenta obras que han sido estrenadas y se han grabado o conservado de forma completa o parcial en partituras actualmente accesibles. Para ello se ha contado con la colaboración del propio Bianchi y del productor Sergio Tapia Sandoval, pero debe advertirse que está pendiente la sistematización completa del archivo personal del compositor, la recuperación de todas sus partituras, el registro pormenorizado de sus grabaciones fonográficas y el acceso a ellas. Por tanto, una futura investigación asentada respecto de esas tareas previas podría aportar datos acerca de este corpus que modifiquen aquellos que expongo aquí.

La obra musical religiosa de Bianchi se puede agrupar en dos grandes categorías: música navideña y música litúrgica. Mientras la segunda está concebida como parte de la liturgia de un servicio específico (misa, tedeum), la primera corresponde a piezas vinculadas con la celebración de la Navidad y a formatos poético-tradicionales tradicionales y populares urbanos. Lo que no obsta, sin embargo, para que una pieza de música litúrgica se presente en el contexto de un concierto o que alguna pieza de música navideña se pueda integrar en un servicio litúrgico especial.

Dentro de la música navideña se puede diferenciar entre canciones independientes o "villancicos ${ }^{4}$ " de formato corto y el oratorio La historia de Belén que está articulado por diferentes piezas, entre ellas algunas que pueden funcionar como obras independientes. Además, en la música litúrgica se pueden distinguir tres rubros: los himnos y piezas ocasionales con textos litúrgicos, himnos y piezas con textos de otra procedencia y misas.

2 León 2011: 94.

3 Bianchi se formó previamente como pianista, siendo alumno del destacado maestro Alberto Spikin Howard en el Conservatorio Nacional de Música en la década de 1930.

4 Como sabemos, la historia del género villancico es compleja y de larga data. En el contexto de este trabajo, atendiendo al uso habitual del término en Chile, me refiero a "canción navideña" en un sentido amplio. 
En la siguiente sección haré una presentación general de la obra de Bianchi según estas categorías. Se mencionarán aspectos generales respecto de la estructura de las letras y su procedencia, el esquema formal, rasgos métricos y tonales, además de información acerca de su contexto de creación en los casos pertinentes. Todas las piezas están escritas para coro mixto con algún tipo de acompañamiento instrumental, con una sola excepción que se indicará oportunamente. Debido a la diversidad de versiones y arreglos que el propio compositor y otros han hecho de estas piezas, en este artículo tomo en cuenta la instrumentación desplegada en las transcripciones digitales y copias de manuscritos que ha facilitado Sergio Tapia ${ }^{5}$.

\section{PRESENTACIÓN GENERAL DEL REPERTORIO RELIGIOSO DE BIANCHI}

\subsection{Música navideña: piezas independientes}

El catálogo de obras navideñas en particular y religiosas en general de Bianchi comienza cronológicamente con la canción Otra Navidad 6 . La pieza fue escrita hacia 1955, durante la estancia de Bianchi en Lima (1951-55), época en la que trabajó en radio El Sol de esa ciudad. La letra pertenece a Juan Rivero, abogado y amigo de la familia del compositor que en esa misma época se estableció también en Lima y contribuyó con versos para otras obras de Bianchi ${ }^{7}$. El texto presenta cuatro estrofas heptasílabas.

\begin{tabular}{|c|c|}
\hline $\begin{array}{l}\text { 1. Esperando otra noche } \\
\text { Noche de Navidad, } \\
\text { Viven todos los hombres } \\
\text { En cristiana ansiedad }\end{array}$ & $\begin{array}{l}\text { 3. La ilusión por la espera } \\
\text { De nueva Navidad } \\
\text { Bellos hace los sueños } \\
\text { Y hace dulce el hogar. }\end{array}$ \\
\hline $\begin{array}{l}\text { 2. La estrellita señala } \\
\text { Un eterno ideal } \\
\text { La suprema esperanza } \\
\text { De la felicidad. }\end{array}$ & $\begin{array}{l}\text { 4. Nochebuena nos trae } \\
\text { Mensaje fraternal } \\
\text { Que la estrella nos guíe } \\
\text { Hacia un mundo de paz }\end{array}$ \\
\hline
\end{tabular}

La puesta en música de Bianchi presenta la cifra métrica de $6 / 8$ y tiene un carácter reposado, con mayor vivacidad en la estrofa $3^{\mathrm{a}}$. El mismo esquema melódico-armónico se usa en las estrofas $1^{\mathrm{a}}, 2^{\mathrm{a}}$ y $4^{\mathrm{a}}$, con un contraste en la estrofa $3^{\text {a }}$. En las grabaciones disponibles se repiten las últimas dos estrofas, de modo que

\footnotetext{
5 Los detalles de las versiones consultadas, tanto transcripciones como copias de manuscritos, así como de registros fonográficos, se pueden encontrar en el Catálogo selectivo de las obras musicales de Vicente Bianchi Alarcón confeccionado por Julio Garrido Letelier que se publica en este mismo número de $R M C H$.

6 Catálogo, O-33.

7 Las tonadas Campito de mi tierra (O-27) y Chile compañero (O-28), así como el vals peruano Peruanita bonita (O-31).
} 
el esquema formal resultante es AABABA, con A en la tonalidad de do mayor y B en la bemol mayor. La partitura, por su parte, presenta dos opciones tonales para cantar la última estrofa en el cierre de la pieza, una en do mayor y la otra en mi bemol mayor.

De la década de 1960 proceden las piezas Guitarra de Nochebuena y Burrito de Belén ${ }^{8}$, ambas con letras escritas por Germán Becker Ureta (1927-2017), escritor y director de cine con el que Bianchi colaboró en otros proyectos ${ }^{9}$. Estas dos canciones fueron registradas en el lado B del LP Misa a la Chilena y otros 6 temas chilenos (1965) y posteriormente han aparecido en otras recopilaciones fonográficas. Guitarra de Nochebuena presenta cuatro cuartetas octosílabas agrupadas de a dos, más otra cuarteta que funciona como estribillo.

\begin{tabular}{|c|c|c|}
\hline $\begin{array}{c}\text { 1. En el silencio del campo } \\
\text { Cuando el grillo se ha dormido } \\
\text { Se oye sonar lejano } \\
\text { De una guitarra el tañido. }\end{array}$ & $\begin{array}{c}\text { Guitarra de Nochebuena } \\
\text { Con cuerda de plata y oro } \\
\text { Guitarra de Nochebuena } \\
\text { Para el niñito que adoro }\end{array}$ & $\begin{array}{c}\text { 3. La luna despierta al grillo } \\
\text { La luna juega en las ramas } \\
\text { Los cerros se ven azules } \\
\text { Como en la hora del alba. }\end{array}$ \\
\hline $\begin{array}{c}\text { 2. El sauce baja sus ramas } \\
\text { Tocando el agua serena } \\
\text { Solo se escucha tu canto, } \\
\text { Guitarra de Nochebuena. }\end{array}$ & & $\begin{array}{c}\text { 4. El río calma su paso } \\
\text { El agua besa la arena } \\
\text { Aleluya de los campos, } \\
\text { Guitarra de Nochebuena. }\end{array}$ \\
\hline
\end{tabular}

La pieza presenta repetición de los últimos dos versos en cada cuarteta par y en el estribillo. Está en la tonalidad de sol mayor, con pasos transitorios a si bemol mayor al final de cada cuarteta par y del estribillo. Tiene un carácter de tonada, con cifra de compás en $6 / 8$.

Burrito de Belén, por su parte, corresponde a un trote o "huaynito" (como dice en la partitura) en 2/4 y presenta un esquema similar al de Guitarra de Nochebuena con estrofas y estribillo que corresponden a cuartetas octosílabas.

\begin{tabular}{|c|c|}
\hline 1. Un burro de orejas largas, & 2. La madre cuidaba al Niño \\
De cola como plumero, & Que en la cuna dormitaba, \\
Un burro de esos de carga & El burro de orejas largas \\
Llegó al pesebre primero. & Con su aliento lo entibiaba. \\
\hline Burrito de orejas largas & 3. Los ángeles que bajaron \\
El del portal de Belén & Hasta el portal de Belén \\
Ven a cuidar a mi niño, & Azúcar dieron al burro, \\
Mi niño se porta bien. & Se había portado bien. \\
\hline
\end{tabular}

8 Catálogo, O-60 y O-65, respectivamente.

9 En las marchas Volvamos al estadio (O-96) y Gloria en el mar (O-97), en los espectáculos masivos conocidos como "clásicos universitarios" que Becker dirigió por varios años y en los filmes Ayúdeme usted compadre (1968) y Volver (1969). 
Los versos $2^{\circ}$ y $4^{\circ}$ de cada estrofa se repiten, así como los dos últimos versos del estribillo. Las estrofas están en la tonalidad de sol menor, con paso transitorio a si bemol mayor y cadencia final en sol mayor, mientras el estribillo se encuentra íntegramente en sol mayor.

A las piezas anteriores se agregan Refalando en Navidad y En Belén, en Belén, ambas con letra y música de Bianchi. Refalando en Navidad ${ }^{10}$, basada en un ritmo de refalosa en 6/8, presenta dos estrofas y un estribillo ("escobillado"). Cada estrofa corresponde a una cuarteta con los primeros dos versos octosílabos, el tercero hexasílabo y el último heptasílabo. El estribillo consiste en una cuarteta con los primeros dos versos eneasílabos y los dos siguientes octosílabos.

\begin{tabular}{|c|c|c|}
\hline 1. San José está contemplando & Refalemos en Navidad & Los pastores y los reyes \\
Con María en el portal & Que la estrella brillando está & Han venido a saludar \\
Al recién nacido & Póngale pino m'hijita & Con sus "engañitos" \\
Tendido en el pajar. & Que el Niño se va a alegrar & Al Niño celestial. \\
\hline
\end{tabular}

En la puesta en música, los primeros dos versos se repiten inmediatamente y después de los dos versos siguientes en cada estrofa. En el caso del estribillo se repiten inmediatamente los dos primeros versos y a continuación los dos siguientes. La pieza está en la tonalidad de re mayor.

En Belén, en Belén $n^{11}$ fue escrita en 1974 y su letra consiste en un estribillo de cuatro versos (heptasílabos los impares, que en realidad son un solo verso que se repite, octosílabos los pares) y dos estrofas de cuatro versos, cada uno de ellos con distinto número de sílabas $(13,5,7,9)$.

\begin{tabular}{|c|c|c|}
\hline En Belén, en Belén & 1. Hay un halo de paz y las & 2. Cristo es paz y esperanza, es \\
Ha nacido el Salvador, & manos abiertas & felicidad, \\
En Belén, en Belén, & Llenas de amistad & Luz del corazón, \\
Hoy nació nuestro Señor. & Los pastores anuncian & Cielo y tierra se alegran, \\
& Que hoy ha nacido el Redentor & Hoy ha nacido el Niño Dios. \\
\hline
\end{tabular}

Esta canción está en 2/2 y tiene carácter alegre, con un estilo que alude a músicas populares de raíz afroamericana. Está en la tonalidad de re mayor, con modulaciones transitorias a la tonalidad de la dominante (la mayor) en las estrofas. La pieza fue incorporada como parte del espectáculo Cascanueces cascarrabias de René Ulloa, producido por la Universidad de Concepción en $2015^{12}$.

10 Catálogo, O-66.

11 Catálogo, O-83.

12 www.youtube.com/watch?v=r0zCUJCm1FY; www.youtube.com/watch?v=ZD8FVzKEXk8 [último acceso: 23 de oct. de 2017]. 


\subsection{Música navideña: Oratorio La historia de Belén}

Junto con las cuatro piezas mencionadas, en el rubro de música navideña de Bianchi se debe mencionar el oratorio La historia de Belén. Sus antecedentes se remontan a la participación regular de Bianchi en la celebración de la Misa del Gallo en la parroquia de Santa Marta en La Reina, donde presentó por primera vez la obra en 196413. Posteriormente en los LP Navidad en Chile (1965) y Chile canta a su niño Dios (1973) aparecen algunas canciones que son parte de La historia de Belén. En 1988 el compositor presentó una nueva versión del oratorio, con presentación de actores y actrices cantantes que representan tanto a los protagonistas de la historia como a personajes chilenos típicos. De acuerdo con el testimonio de Bianchi, la concepción definitiva de la obra es audiovisual y televisiva, pero hasta hoy no ha habido acogida de ningún canal para presentar o registrar la obra. Pese a esto pudo ser ejecutada en la Quinta Vergara de Viña del Mar ${ }^{14}$.

La obra consiste en trece piezas cantadas, con letra y música de Bianchi, que en su ejecución se intercalan con un relato extraído de los evangelios del Nuevo Testamento, a cargo de un narrador. Las piezas son Prólogo, Elogio al trabajo, La anunciación, Magnificat, Ronda angelical a María, Encuentro del ángel con José, Lectura del edicto, La peregrinación, Noche prodigiosa, Canción de cuna (al niño Dios), Vamos pastores, vamos, Los reyes magos, Aleluya al Señor. De estas piezas, la $9^{\mathrm{a}}, 10^{\mathrm{a}} \mathrm{y} 11^{\mathrm{a}}$ han sido grabadas aparte y en ellas me enfocaré en esta ocasión.

Noche prodigiosa $\left(\mathrm{N}^{\circ} 9\right)^{15}$ presenta cuatro estrofas que contrastan desde un punto de vista métrico. Las dos primeras son cuartetas octosílabas con rima en los versos pares, mientras la tercera presenta cinco versos, los tres primeros son eneasílabos anfibráquicos, el cuarto verso heptasílabo y el último decasílabo. La última estrofa, por su parte, presenta cuatro versos con distinta métrica cada uno, con repetición del primero después del cuarto.

\begin{tabular}{|c|c|}
\hline $\begin{array}{c}\text { 1. Todo es quietud en Belén, } \\
\text { Noche de serenidad, } \\
\text { Como esperando el milagro } \\
\text { Feliz de la humanidad. }\end{array}$ & $\begin{array}{c}\text { 3. De pronto en la gruta aparecen } \\
\text { Destellos de brillos de sol } \\
\text { Los ángeles bajan y cantan: } \\
\text { Ha nacido Jesús, }\end{array}$ \\
Ha nacido Jesús niño Dios.
\end{tabular}

Se puede observar que la diferencia métrica en las estrofas coincide con cambios de carácter en el contenido de la letra. Esto se plasma además en la puesta en

13 Sattler 2015: 118.

14 León 2011: 102.

15 Catálogo, O-63. 
música. Las primeras dos estrofas están en $6 / 8$, ritmo lento y carácter contemplativo, en la tonalidad de mi bemol menor. La tercera tiene un carácter más vivaz y rápido, con modulaciones por las tonalidades de si bemol mayor, sol mayor y fa mayor. Finalmente, la última estrofa tiene un aire más marcial y alegre, en $2 / 4$ y con la tonalidad de si bemol mayor.

Canción de cuna al Niño Dios $\left(\mathrm{N}^{\mathrm{o}} 10\right)^{16}$ tiene un ritmo ternario lento y cuatro estrofas. Las estrofas $1^{\mathrm{a}}, 2^{\mathrm{a}}$ y $4^{\mathrm{a}}$ son cuartetas cuyo primer verso es octosílabo, el segundo y el cuarto son endecasílabos y el tercero es dodecasílabo. En cambio, la estrofa $3^{\text {a }}$ es una cuarteta cuyo segundo verso es octosílabo, el cuarto es eneasílabo anfibráquico y los impares son heptasílabos. El verso de la última estrofa se repite en la puesta en música.

\begin{tabular}{|c|c|}
\hline $\begin{array}{c}\text { 1. Oh niñito duerme ya, } \\
\text { Tus ojos risueños entornarás } \\
\text { Y un hada muy bella a tu lado vendrá } \\
\text { Regalos y dones te entregará. }\end{array}$ & $\begin{array}{l}\text { 3. Todo ya es alegría, } \\
\text { Fiesta de la humanidad, } \\
\text { Niño, tú eres mensaje } \\
\text { Mensaje de amor y de paz. }\end{array}$ \\
\hline $\begin{array}{l}\text { 2. Velando tu sueño están } \\
\text { Los ángeles todos, papá y mamá } \\
\text { También los pastores en tierno solaz } \\
\text { Para acariciarte y amarte más. }\end{array}$ & $\begin{array}{l}\text { 4. El Niño ya se durmió, } \\
\text { Sus suaves manitas las empuñó } \\
\text { Mañana en el alba habrá trinos de amor } \\
\text { El mundo sabrá que ha nacido Dios }\end{array}$ \\
\hline
\end{tabular}

Su esquema formal es similar al de Otra Navidad, con un mismo plan melódicoarmónico usado en las estrofas $1^{\mathrm{a}}, 2^{\mathrm{a}}$ y $4^{\mathrm{a}}$, en la tonalidad de la bemol mayor, y un contraste en la estrofa $3^{\text {a }}$ la que se presenta en do mayor y modula hacia mi bemol mayor. Su cifra métrica es $6 / 8$, alternada con $9 / 8$ en las estrofas ${ }^{17}$.

Vamos pastores, vamos $\left(\mathrm{N}^{\circ} 11\right)^{18}$ fue compuesta en 1987, está escrita en la tonalidad de re mayor, cifra métrica de $6 / 8$ y su estilo se asocia con músicas tradicionales de raigambre española.

\begin{tabular}{|c|c|c|}
\hline $\begin{array}{c}\text { 1. Vamos pastores, vamos, } \\
\text { Vamos todos a Belén } \\
\text { A ver al niño Jesús }\end{array}$ & $\begin{array}{c}\text { 2. Vamos pastores, vamos, } \\
\text { No le hagamos esperar } \\
\text { Es Cristo Dios que ha nacido } \\
\text { Y lo vamos a adorar } \\
\begin{array}{c}\text { Vamos, vamos pastores vamos, } \\
\text { Cantándole hasta Belén. }\end{array}\end{array}$ & $\begin{array}{c}\text { 3. Vamos pastores vamos, } \\
\text { Nuestros dones a entregar } \\
\text { La estrella nos va alumbrando } \\
\text { La ruta para llegar, } \\
\text { Que está cerca ya el portal. }\end{array}$ \\
$\begin{array}{c}\text { Y con un corderito tierno } \\
\text { El Niño se va a alegrar. }\end{array}$ \\
$\begin{array}{c}\text { Aleluya, aleluya, aleluya } \\
\text { Aleluya, aleluya, aleluya }\end{array}$ & $\begin{array}{c}\text { Aleluya, aleluya, aleluya } \\
\text { Aleluya, aleluya, aleluya }\end{array}$ & $\begin{array}{c}\text { Aleluya, aleluya, aleluya } \\
\text { Aleluya, aleluya, aleluya }\end{array}$ \\
\hline
\end{tabular}

16 Catálogo, O-64.

17 Tanto Noche prodigiosa como la Canción de cuna al Niño Dios son piezas a las que se puede acceder por un registro subido a Youtube del LP Chile canta a su niño Dios, bajo el título Chile canta al Niño Jesús (www.youtube.com/watch?v=YV8i2ZcQ2Kc\&t=700s [último acceso: 23 de oct. de 2017]).

18 Catálogo, O-105. 
Si bien estas tres piezas pueden funcionar como trozos independientes, en el caso de Noche prodigiosa su peculiar estructura le otorga rasgos más bien de pieza de enlace entre La peregrinación $\left(\mathrm{N}^{\circ} 8\right)$ y Canción de cuna al niño Dios.

\subsection{Himnos y piezas ocasionales con texto litúrgico}

El Ave María ${ }^{19}$ de 1965 fue escrito para coro mixto a capela con el fin de celebrar la ceremonia de primera comunión de Silvana Bianchi Murúa, hija del compositor $^{20}$. El texto corresponde a aquel del rezo tradicional, por tanto prescindo de presentarlo. La pieza está escrita en $6 / 8$, con un estilo de tonada y esquema de composición desarrollada, sin secciones que se repitan. La tonalidad oscila entre si menor y re mayor, finalizando en esta última tonalidad.

A continuación se debe mencionar el Te Deum laudamus ${ }^{21}$ [A ti, oh Dios, te alabamos] para coro mixto y orquesta. Ese himno fue encargado por el cardenal Raúl Silva Henríquez (1907-1999) en 1969 para ser cantado en el tedeum de fiestas patrias en Chile ${ }^{22}$. La pieza fue parte de esta celebración anual en la catedral católica de Santiago hasta el 2000, y posteriormente en la misma festividad en la comuna de $\mathrm{Macul}^{23}$. La letra corresponde a una traducción parcial del himno original en latín, hecha por el presbítero salesiano Felipe Lázaro Urrizola (1912-2005) ${ }^{24}$, con un total de ocho estrofas con tres o cuatro versos cada una (excepto la última con solo dos versos), con diversos números de sílabas por cada verso.

\begin{tabular}{|c|c|c|}
\hline $\begin{array}{l}\text { 1. A ti, oh Dios, te alabamos } \\
\text { Y por Señor te aclamamos } \\
\text { A ti, oh Dios, oh Padre eterno, } \\
\text { La tierra entera te adora. }\end{array}$ & $\begin{array}{l}\text { 4. Señor Jesucristo, } \\
\text { Hijo del Padre, luz de los } \\
\text { hombres, } \\
\text { Te rogamos: ilumínanos. }\end{array}$ & $\begin{array}{l}\text { 6. Salva, Señor, a tu pueblo, } \\
\text { A la herencia de tu gracia, } \\
\text { Dirígenos con tu diestra } \\
\text { Y danos la vida eterna. }\end{array}$ \\
\hline $\begin{array}{l}\text { 2. A ti los ángeles y todo el cielo } \\
\text { Las potestades y querubines } \\
\text { Con voz eterna y amor } \\
\text { proclaman: }\end{array}$ & $\begin{array}{c}\text { 5. A ti, Espíritu Consolador, } \\
\text { Lengua de fuego, llama de } \\
\text { amor, } \\
\text { Te pedimos: santifícanos. }\end{array}$ & $\begin{array}{l}\text { 7. Ten piedad de nosotros } \\
\text { Y guíanos con bondad. } \\
\text { Llévanos hacia el Padre, } \\
\text { A su reino celestial. }\end{array}$ \\
\hline $\begin{array}{c}\text { 3. Santo, Santo, Santo } \\
\text { Eres Señor, Dios del Universo } \\
\text { Llenos están el cielo y la tierra } \\
\text { de tu gloria } \\
\text { Hosanna en el cielo. }\end{array}$ & & $\begin{array}{l}\text { 8. No seremos confundidos, } \\
\text { Confiamos en ti, Señor. }\end{array}$ \\
\hline
\end{tabular}

19 Catálogo, O-68.

20 León 2011: 101.

21 Catálogo, O-75.

22 León 2011: 100.

23 Entrevista a V. Bianchi, 16 de noviembre de 2016.

$24 \mathrm{http}: / /$ boletinsalesiano.cl/fallece-el-salesiano-padre-felipe-lazaro/ [último acceso: $18 \mathrm{de}$ oct. de 2017]. 
El himno presenta una alternancia entre $4 / 4$ y $2 / 4$ y su plan tonal es progresivo. La $1^{\text {a }}$ estrofa ("A ti, oh Dios, te alabamos”) está en do mayor. Las dos siguientes (“A ti los ángeles del cielo", "Santo, santo, santo") están fundamentalmente en mi mayor. Las estrofas $4^{\mathrm{a}}$ y $5^{\mathrm{a}}$ presentan rasgos modales y reminiscentes del canto gregoriano, oscilando entre mi menor y mi dorio. Finalmente, las últimas estrofas (desde "Salva, Señor, a tu pueblo") se estabilizan en re mayor.

La siguiente pieza en este rubro es Oh Señor envía tu Espiritu ${ }^{25}$ para coro mixto y orquesta. El origen de esta obra fue la solicitud hecha a las autoridades eclesiásticas católicas por Salvador Allende Gossens (1908-1973), Presidente de la República de Chile proclamado el 24 de octubre de 1970 por el Congreso pleno, para llevar a cabo un servicio de acción de gracias de carácter ecuménico por su elección e inicio de su mandato ${ }^{26}$. Este servicio se realizó el 3 de noviembre de 1970 en la catedral católica y ha sido a menudo calificado como el "primer tedeum ecuménico" en Chile, aunque no se trató del tedeum de fiestas patrias que a partir de 1971 adquirió también un carácter ecuménico. Sin embargo, las autoridades eclesiásticas estimaron que para esta ocasión no correspondía el canto del Te Deum propiamente tal, por tanto se escogió como pieza central del servicio este otro texto que corresponde a una traducción parcial al castellano de los versos Emitte Spiritum tuum et creabuntur / Et renovabis faciem terrae (basados en el Salmo 104:30 y vinculados con la liturgia de Pentecostés) y de la secuencia medieval Veni Sancte Spiritus ${ }^{27}$. Los versos "Oh Señor, envía tu espíritu / que renueve la faz de la tierra” funcionan como antífona que alterna con las estrofas de la secuencia, las que corresponden a cuartetas hexasílabas.

\begin{tabular}{|c|c|}
\hline & $\begin{array}{l}\text { 3. Ven, Consolador } \\
\text { Bueno y soberano, } \\
\text { ANT. Oh Señor, envía tu espíritu } \\
\text { Que renueve la faz de la tierra. } \\
\text { Celestial regalo. }\end{array}$ \\
\hline 1. Ven a nuestras almas, & Oh las almas, \\
Oh Espíritu Santo & Descanso al trabajo, \\
Y envíanos del cielo & Templanza en lo ardiente \\
De tu luz un rayo. & Consuelo en el llanto \\
\hline 2. Padre de los pobres, & 5. Aumento en virtudes, \\
Con tus dones santos & Haz que merezcamos \\
De los corazones & Da el eterno gozo \\
El único amparo. & Da el feliz descanso. \\
\hline
\end{tabular}

25 Catálogo, O-78.

26 León 2011: 101.

27 La traducción de esta secuencia es el resultado del aporte de varios colaboradores en el curso de la historia, entre ellos el poeta español Juan de Jáuregui (1583-1641) y el obispo protestante español Juan Bautista Cabrera (1837-1916). 
En la puesta en música se presenta primero la antífona, luego la estrofa $1^{\mathrm{a}} \mathrm{y}$ después nuevamente la antífona. Siguen las estrofas $2^{\mathrm{a}}$ y $3^{\mathrm{a}}$, antífona, estrofas $4^{\mathrm{a}}$ y $5^{\mathrm{a}}$, antífona, nuevamente la estrofa $1^{\mathrm{a}}$ y antífona. En consecuencia, el esquema formal corresponde a un ABACACABA, donde A (antífona) y B (estrofa $1^{\mathrm{a}}$ ) están en la mayor, mientras $\mathrm{C}$ (estrofas $2^{\mathrm{a}}$ y $3^{\mathrm{a}}, 4^{\mathrm{a}}$ y $5^{\mathrm{a}}$ ) está en la menor.

Por su parte, el Magnificat $t^{28}$ fue compuesto en 1989 para coro mixto y orquesta. El texto corresponde a una versión en castellano del cántico litúrgico tradicional de este nombre, aunque la pieza comienza con la triple reiteración de la palabra "Magnificat" (latín). Después de esta frase, se presenta la antífona que alterna con cuatro estrofas de cuatro versos con un número de sílabas que oscila entre 10 y 12, para terminar con una doxología.

\begin{tabular}{|c|c|}
\hline $\begin{array}{l}\text { Magnificat, magnificat, magnificat } \\
\text { ANT.: Mi alma engrandece al Señor, } \\
\text { Mi espiritu se alegra en Dios mi Salvador. }\end{array}$ & $\begin{array}{c}\text { 3. Derribó de su trono a poderosos } \\
\text { Y ensalzó a los que fueron humillados. } \\
\text { Los hambrientos muchos bienes recibieron } \\
\text { Y a los ricos vacíos despidió. }\end{array}$ \\
\hline $\begin{array}{l}\text { 1. Porque ha puesto sus ojos en mí } \\
\text { Sin mirar la pequeñez de su esclava. } \\
\text { Desde ahora, y por los siglos de los siglos, } \\
\text { Dichosa me dirán eternamente. }\end{array}$ & $\begin{array}{l}\text { 4. Ayudó a Israel, su servidor, } \\
\text { Pues lo había prometido a nuestros padres, } \\
\text { Recordando su amor por Abraham } \\
\text { Y su raza, a lo largo de los siglos. }\end{array}$ \\
\hline $\begin{array}{l}\text { 2. Grandes cosas por mí ha hecho el Poderoso } \\
\text { Y su nombre venerado es Santo. } \\
\text { Dios extiende su gran misericordia } \\
\text { En favor de sus fieles que le aman }\end{array}$ & $\begin{array}{c}\text { 5. Gloria al Padre y a Cristo el Señor } \\
\text { Y al Espíritu que habita en nuestras almas. } \\
\text { Amén. }\end{array}$ \\
\hline
\end{tabular}

La cifra de compás es $4 / 4$ y la tonalidad es la menor natural, aunque la entonación de la frase "Magnificat" concluye en dominante mayor de la y la pieza termina con el acorde de subdominante mayor (re mayor).

\subsection{Piezas ocasionales con textos de otra procedencia.}

A este grupo corresponde en primer lugar Amén, Señor, Amén (1969) ${ }^{29}$, pieza para coro mixto y orquesta con letra del compositor. Comienza con una aclamación ("Aleluya") que deja paso a dos estrofas de cuatro versos, en las que el primero y el último corresponden a la frase "Amén Señor Amén”. Sigue una tercera estrofa en forma de cuarteta octosílaba, luego un retorno a las estrofas $1^{\mathrm{a}}$ y $2^{\mathrm{a}}$ para terminar con la reiteración del último verso. 


\begin{tabular}{|c|c|}
\hline $\begin{array}{c}\text { Aleluya, aleluya, } \\
\text { aleluya, aleluya } \\
\text { Aleluya al señor, aleluya }\end{array}$ & $\begin{array}{c}\text { 4. Amén Señor Amén } \\
\text { Que nos cubra tu grandeza } \\
\text { Nos proteja y nos dé fuerza } \\
\text { Amén Señor Amén }\end{array}$ \\
\hline $\begin{array}{c}\text { 1. Amén Señor Amén } \\
\text { Que nos cubra tu grandeza } \\
\text { Nos proteja y nos dé fuerza } \\
\text { Amén Señor Amén }\end{array}$ & $\begin{array}{c}\text { 5. Amén Señor Amén } \\
\text { Que tu espíritu ilumine }\end{array}$ \\
Y nos guíe al buen camino \\
Amén Señor Amén
\end{tabular}

La aclamación inicial alterna los compases de 4/4 y 3/4, con tempo allegretto moderato y en la tonalidad de re mayor. Se da paso a la $1^{\text {a }}$ y la $2^{\mathrm{a}}$ estrofa, las que comparten la misma música en compás de $6 / 8$ y tempo andantino, con un despliegue rítmico-métrico que recuerda a aquel de las tonadas típicas chilenas. La $3^{\mathrm{a}}$ estrofa se presenta en la tonalidad de la mayor con algunos cambios melódicos. Como se ha dicho, se retorna a las primeras dos estrofas y se clausura con "Amén Señor, amén, amén” afirmando re mayor. El esquema formal resultante, por tanto, es en gran medida un ABA con una introducción.

Así como el Ave María fue escrito para celebrar la primera comunión de su hija Silvana, la canción María de mi pueblo ${ }^{30}$ fue compuesta en 1970 para celebrar el mismo sacramento en el caso de otra hija suya, Bernardita Bianchi Murúa ${ }^{31}$. La letra pertenece al poeta y escritor Rubén Campos Aragón (1930-1999), el que colaboró con Bianchi en las partes del propio de la Misa de la Cruz del Sur. El texto consiste en doce versos con un número de sílabas que oscila entre seis y once. En cuanto a su contenido, se puede observar que se trata de una reescritura del Ave María tradicional.

30 Catálogo, O-81.

31 León 2011: 101. 
Que Dios te guarde María, María de mi pueblo,

Llena eres de trigos y viñas Y el tiempo es contigo.

Elegida eres tú entre todas,

Mujer de greda y alegría, Que maduras nostalgias y cosechas
María de mi pueblo, Brazo derecho de la chacra Sonríenos inviernos y sequías Ahora y en la hora en punto De nuestro final en la tierra Amén.

La pieza está en 6/8 y en la tonalidad de si bemol mayor. Aunque funciona como pieza autónoma, fue incorporada como canto de comunión en la edición definitiva de la Misa a la Chilena.

La pieza María de Chile (1984) ${ }^{32}$, "letanías marianas", tiene texto del compositor, basado en una antigua tradición de devoción mariana. La antífona consiste en cuatro versos endecasílabos y abre las letanías. Le sigue una serie de ocho versos, nuevamente antífona, otra serie de ocho versos, antífona y dos versos de clausura.

\begin{tabular}{|c|c|}
\hline & María, puerta del cielo, \\
ANT.: Salve María misericordiosa & María, mar y montaña, \\
Madre querida, llama luminosa. & María, germen de vida, \\
Salve María misericordiosa & María, hermosa y soberana. \\
Danos tu gracia, madre bondadosa. & María, reina del mundo, \\
& María, somos tus fieles, \\
& María, Virgen del Carmen, \\
María, Madre de Chile.
\end{tabular}

La pieza está en 2/2 y presenta tonalidad progresiva: la primera presentación de la antífona está en la bemol mayor, al igual que la serie de versos que le sigue, la segunda presentación y la segunda serie están en la mayor, la última presentación y los versos finales están en si bemol mayor.

La Oración por la paz de Chile ${ }^{33}$ para coro mixto y orquesta tiene letra del cardenal Silva Henríquez, la que el compositor acortó con la autorización del prelado ${ }^{34}$, y fue estrenada en el tedeum de fiestas patrias de 1974. Esta pieza ha sido usada

32 Catálogo, O-100.

33 Catálogo, O-82.

34 Entrevista a V. Bianchi, 16 de noviembre de 2016. 
durante la ceremonia del tedeum en el momento del saludo de paz. El poema tiene siete versos con distinta longitud.$$
\text { Paz, paz, paz }
$$ \\ A los hombres de Chile y el mundo. \\ Padre Todopoderoso, \\ Míranos reunidos en tu hijo Jesucristo. \\ Por nuestro amor a esa paz en la tierra \\ Que llegue a los pueblos tu luz verdadera \\ Por los siglos de los siglos. \\ Amén, amén, amén.
}

La pieza está en 2/4 y en la tonalidad de la mayor, con un esquema formal concatenado, sin repetición de secciones.

Totus tuo (1986) ${ }^{35}$ tiene letra y música de Bianchi. La creación de esta obra se vincula con la visita realizada por el papa san Juan Pablo II (1920-2005) a Chile en 1987. El lema apostólico de este pontífice era precisamente Totus tuus ego sum! (“Todo tuyo yo soy!”), con el que se encomendaba a la protección de la Virgen María. La letra consiste en cuatro cuartetas octosílabas agrupadas de a dos, más un estribillo articulado asimismo por dos cuartetas de versos octosílabos, con excepción del primero en ambas ("Salve, salve María”) que es heptasílabo.

\begin{tabular}{|c|c|c|}
\hline $\begin{array}{l}\text { 1. Llenen el cielo y la tierra, } \\
\text { Cánticos plenos de amor } \\
\text { Por María madre nuestra } \\
\text { Toda gloria y corazón. }\end{array}$ & $\begin{array}{c}\text { Salve, salve Maria } \\
\text { Salve, aurora de esperanza } \\
\text { Salve, reina de amor } \\
\text { Bendita de Dios sin mancha. }\end{array}$ & $\begin{array}{l}\text { 3. Blanca señora del cielo, } \\
\text { Virgen del Carmen María } \\
\text { Esperanza de los pueblos } \\
\text { Esperanza de alegría. }\end{array}$ \\
\hline $\begin{array}{l}\text { 2. Dios quiso darle la gloria } \\
\text { De brotar en santidad } \\
\text { Concibiendo a Jesucristo } \\
\text { Por salvar la humanidad. }\end{array}$ & $\begin{array}{c}\text { Salve, salve María } \\
\text { Salve Virgen del dolor } \\
\text { Iluminanos la senda } \\
\text { Que nos lleve hasta el Señor. }\end{array}$ & $\begin{array}{l}\text { 4. Madre de Dios y los hombres } \\
\text { Fuente de luz y bondad } \\
\text { Enseñadnos el camino } \\
\text { De la paz y la verdad. }\end{array}$ \\
\hline
\end{tabular}

Con excepción de una breve introducción en 4/4, la cifra de compás predominante es 2/2. Las estrofas están en la tonalidad de mi mayor y se cantan al unísono, mientras el estribillo se encuentra en la mayor y está escrito para cuatro voces. Debido a que la pieza termina con la frase “Amén, amén” con una cadencia clásica en esta última tonalidad, se puede considerar la mayor como verdadero tono principal, de modo que las estrofas pueden interpretarse en tonalidad de dominante.

35 Catálogo, O-104. 
A Santa Teresa de los Andes (1992) ${ }^{36}$, última obra en este rubro, tiene un texto del P. Demetrio Bravo Santibáñez (1904-1993). Este último fue el que se acercó a Bianchi para solicitarle poner en música su texto ${ }^{37}$. Se trata de tres estrofas y un estribillo, todos consistentes en cuatro versos que alternan entre 11 y 12 sílabas.

\begin{tabular}{|c|c|}
\hline $\begin{array}{l}\text { 1. Cual lucero de iglesia en mi bandera } \\
\text { Resplandeces en fulgor de tu Carmelo } \\
\text { Eres tú en sus pliegues la primera } \\
\text { Que entreabres visión de nuestro cielo }\end{array}$ & $\begin{array}{l}\text { 2. Chacabuco nos guarda el gran tesoro } \\
\text { El gorjeo de su voz en las campiñas } \\
\text { Su jovial corazón, su sangre de oro } \\
\text { Su pasión catequista entre las niñas }\end{array}$ \\
\hline $\begin{array}{l}\text { Todos canten a Dios agradecidos } \\
\text { El haber elegido en nuestra tierra } \\
\text { Una santa ejemplar como Teresa } \\
\text { Que alegría venerarla en nuestra era }\end{array}$ & $\begin{array}{l}\text { 3. Sol y luz tú nublaste en el Carmelo } \\
\text { Por mirar otro sol más verdadero } \\
\text { Sol de amor que tu fe te mandó el cielo } \\
\text { Que en herencia dejaste al mundo entero }\end{array}$ \\
\hline
\end{tabular}

Esta pieza está en 4/4, las estrofas están en re menor y estribillo en re mayor, recurso formal análogo a aquel que se halla en Burrito de Belén.

\subsection{Misas}

Bianchi hasta la fecha ha compuesto tres misas: Misa a la Chilena, Misa del Huaso y Misa de la Cruz del Sur (Misa Sudamericana), de estas la primera y la tercera han sido estrenadas, existen partituras y registros fonográficos accesibles. Me he referido con más detalle a estas dos misas en otros estudios ${ }^{38}$, por tanto me limito aquí a señalar algunos puntos a modo de complemento.

Ante todo, estas misas de Bianchi son obras que remiten a la música típica latinoamericana, tanto chilena (las dos primeras) como continental (la tercera). $\mathrm{Al}$ mismo tiempo, las tres fueron concebidas para el uso litúrgico, pero tanto la primera como la tercera han sido adaptadas para el concierto y para la difusión fonográfica.

La Misa a la Chilena (1964-65) ${ }^{39}$ fue escrita para coro mixto, solistas y conjunto instrumental que incluye, entre otros, charango y guitarra. Fue estrenada y grabada en 1965 con seis partes: Señor ten piedad (araucana), Gloria (refalosa) ${ }^{40}$, Credo (tonada), Santo (tonada), Cordero de Dios (trote) y Cantemos al amor de los amores (canto de salida, Aleluya, cueca), es decir, los cantos colectivos del ordinario de

36 Catálogo, O-108.

37 Entrevista a V. Bianchi, 16 de noviembre de 2016.

38 Guerra 1999, 2014 y 2017. Ver también González, Ohlsen y Rolle 2009: 294-302.

39 Catálogo, O-67.

40 Esta parte de la obra tiene fuertes similitudes con La refalaita, otra refalosa de Bianchi (ver Catálogo, O-43). 
la misa más un canto de salida ${ }^{41}$. Su éxito fue tal que el sello Odeón editó el LP en otros países ${ }^{42}$.

Estimulado por el éxito de la Misa a la Chilena, Bianchi compuso otra obra del mismo género, la Misa del Huaso ${ }^{43}$, en 1967. A diferencia de la primera versión de la Misa a la Chilena, la Misa del Huaso incorpora partes tanto del ordinario como del propio de la misa y con excepción del Gloria, con una matriz rítmica que recuerda al huayno en su parte inicial y final, todas remiten a la tonada: Vamos ya celebrando la santa misa (canto de entrada), Señor ten piedad, Gloria, Credo, Recibe oh Dios el pan que te ofrecemos (ofertorio), Santo, Padrenuestro ${ }^{44}$ y Cordero de Dios. Las letras de las partes del propio son de autoría de Bianchi. No ha sido estrenada ni grabada.

La Misa de la Cruz del Sur o Misa Sudamericana (1969-7045) fue escrita en la misma época de composición del Te Deum laudamus, y fue grabada en 1972, para coro mixto, solistas y conjunto instrumental que incluye charango, cuatro y guitarra. Los textos de los cantos del propio y de salida fueron escritos por Rubén Campos, y cada una de las diez partes representa estilísticamente a uno de los diez países sudamericanos.

Así, sus partes son Paloma sube al lucero (canto de entrada, danza - Bolivia), Señor ten piedad (triste - Perú), Gloria (samba - Brasil, letra en portugués), Credo (guarania y polka - Paraguay), Recibe oh Dios la alegría (ofertorio, zamba - Argentina), Santo (pasillo - Ecuador), Padrenuestro (joropo - Venezuela), Cordero de Dios (bambuco - Colombia), El altar es blanco (canto de paz y comunión, vidalita - Uruguay), Bajo el poncho del sol (canto de salida, Aleluya, cueca - Chile). Se aprecia diversidad métrica entre las partes y un plan tonal global: do mayor - mi menor - do mayor - re mayor - re menor - re mayor - sol mayor - re mayor - la menor - do mayor. Sin embargo, en la grabación original de 1972 estas diez partes están enlazadas por intervenciones litúrgicas puestas en música por el mismo Bianchi y que, a diferencia de las partes cantadas mencionadas, se adscriben más a un estilo eclesiástico neutral que a referencias de música típica.

Después de la composición y grabación de la Misa de la Cruz del Sur, Bianchi decidió expandir definitivamente la Misa a la Chilena al agregar y adaptar el canto de entrada, el ofertorio y el Padrenuestro de la Misa del Huaso, más la pieza María

41 Recordemos que el canto de salida no forma parte de la liturgia de la misa propiamente tal, ni del ordinario ni del propio. Sin embargo, los cantos de salida en estas dos misas de Bianchi son "Aleluyas", y el Aleluya efectivamente forma parte del propio de la misa, pero se ubica entre el Gloria y el Credo.

42 Curiosamente, se hizo una edición peruana donde cambió su nombre por Misa Folklórica tanto en la carátula como en las notas explicativas de Bianchi.

43 Catálogo, O-74.

44 El Padrenuestro es una oración del ordinario y su puesta en música formaba parte del proyecto original de la Misa a la Chilena, pero había sido descartado. León 2011: 96.

45 La época de composición de la Misa de la Cruz del Sur coincide con aquella en que Bianchi colaboró con Germán Becker en el filme musical Volver (1969). Este filme plantea un recorrido musical por distintos países americanos, lo que pudo constituir un estímulo para que Bianchi proyectara esta misa con el mismo impulso. Catálogo, O-76. 
de mi pueblo como canto de comunión, como ya he dicho con anterioridad. De este modo, la edición definitiva de la Misa a la Chilena tiene diez partes, según el modelo de la Misa de la Cruz del Sur. Canto de entrada (Vamos ya celebrando la santa misa), Señor ten piedad, Gloria, Credo, Ofertorio (Recibe oh Dios el pan que te ofrecemos), Santo, Padrenuestro, Cordero de Dios, Comunión (María de mi pueblo), canto de salida (Aleluya). Al tener en cuenta esta edición definitiva y al igual que en la Misa de la Cruz del Sur, se puede observar contrastes métricos entre las partes y un plan tonal general: si bemol mayor - fa menor - re bemol mayor - do mayor - fa mayor - sol mayor - do mayor - fa menor - si bemol mayor - sol mayor.

\section{ASPECTOS ESTILÍSTICOS SIGNIFICATIVOS}

En primer lugar, se puede apreciar que el acercamiento de Bianchi hacia la composición de música religiosa comenzó con las canciones navideñas, lo que implicó desde entonces una afinidad con músicas populares urbanas de raíz tradicional. Creo que este hecho gravitó en el momento de abordar la música litúrgica, específicamente la Misa a la Chilena que acometió en la misma época en que presentaba la primera edición de su oratorio de Navidad La historia de Belén. Sin embargo, la composición del Te Deum laudamus lo condujo a acercarse más a las tradiciones musicales sacras católicas más evocadoras del canto gregoriano y su universo modal. De este modo, exceptuando las misas, el Ave María, María de mi pueblo y en parte Amén Señor Amén, la música litúrgica de Bianchi se asemeja estilísticamente más bien a aquellas tradiciones de música sacra europeas, favorecidas por los sectores más conservadores de la Iglesia católica, que a las músicas típicas tanto de Chile como de Sudamérica. En este sentido, en la versión grabada en 1972 de la Misa de la Cruz del Sur convergen ambas vertientes, en los términos que he comentado anteriormente.

Ahora bien, pese a la presencia de rasgos modales que se puede apreciar en parte de la obra de Bianchi, los que no solo se vinculan con la tradición musical sacra sino con ciertas músicas tradicionales latinoamericanas, el repertorio musical del compositor se enmarca completamente dentro de los parámetros del sistema tonal. De esta manera se encuentran piezas sin modulaciones y eventualmente con algunas funciones transitorias (Guitarra de Nochebuena, Refalando en Navidad, Vamos pastores vamos, Oración por la paz de Chile, Magnificat, todas las partes de la Misa a la Chilena excepto Gloria y Credo, seis partes de la Misa de la Cruz del Sur), otras con oscilación entre una tonalidad menor y su relativa mayor (Ave María, Canto de entrada de la Misa de la Cruz del Sur), otras con intercambio modal (Burrito de Belén, Oh Señor envía tu Espiritu, Canción a Santa Teresa de los Andes, Credo de la Misa de la Cruz del Sur), algunas con modulación a la relativa por intercambio modal (Gloria y Credo de la Misa a la Chilena, Canto de comunión de la Misa de la Cruz del Sur), varias con modulación a la dominante (Amén Señor amén; En Belén, en Belén; Canción al Niño Dios; Otra Navidad) o desde la dominante (Totus tuo, Gloria de la Misa de la Cruz del Sur), y tonalidad progresiva ( Te Deum laudamus, María de Chile, Noche prodigiosa). 
Aparte de estos aspectos tonales generales, es necesario destacar pasajes interesantes desde un punto de vista armónico en algunas piezas, especialmente en las misas. Es el caso de la progresión de enlaces II-V-I que pasa por las tonalidades de si bemol mayor, la bemol mayor y do mayor en los cc. 8-20 del Gloria de la Misa de la Cruz del Sur, la introducción del Canto de entrada en la Misa a la Chilena que pasa por las tonalidades de fa menor y sol menor antes de estabilizarse en si bemol, el uso de la subdominante mayor en tonalidad menor (IV dórico) en el Señor ten piedad de la Misa a la Chilena y en el Santo de la Misa de la Cruz del Sur, el uso del acorde napolitano en la cadencia final del Cordero de Dios en la Misa a la Chilena y como arpegio descendente en el bajo en los cc. 26-32, 35-42 del Cordero de Dios en la Misa de la Cruz del Sur.

Se observa un uso escaso pero significativo de citas musicales. Es el caso de la melodía que se escucha en los primeros compases del Credo en la Misa a la Chilena que se repite en el bajo de los compases iniciales del Ofertorio en la misma obra. Asimismo en los primeros compases de la partitura de Otra Navidad, antes del canto, se aprecia una cita de los últimos compases de la conocida canción navideña Noche de paz de Franz Gruber ${ }^{46}$. En el primer caso se trata de un recurso unificador de la obra y en el segundo de la vinculación explícita que se establece con el repertorio tradicional de la fiesta de Navidad.

En términos de textura, se observa un predominio de homofonía y melodías con acompañamiento, con uso de algunos recursos contrapuntísticos en el caso de obras con orquesta o conjunto instrumental. Con el fin de facilitar la participación comunitaria, el mismo compositor declaró que intencionadamente evitó el uso de contrapunto ${ }^{47}$. Aun así, el comienzo del Credo y el de la sección "Creo en el Espíritu Santo" de la misma pieza en la Misa de la Cruz del Sur constituyen algunos de los escasos ejemplos de contrapunto imitativo en la obra religiosa de Bianchi. Otro ejemplo se encuentra en el Ave María, donde en los primeros compases, oculta en un tejido homofónico, se observa una imitación entre contralto y tenor. En las obras con orquesta los instrumentos suelen duplicar o reforzar las líneas vocales, y en esto llama la atención el papel destacado que suele tener el oboe en dichas piezas.

Varios de los rasgos mencionados se relacionan, de acuerdo con lo que se ha observado, con el propósito de reforzar el sentido de las palabras. Así, en Oh Dios envía tu Espíritu el contraste de modo entre la antífona con la estrofa $1^{\text {a }}$ (partes A y B) y las estrofas $2^{a}$ y $3^{a}$, $4^{a}$ y $5^{a}$ (parte C) evoca aquel entre la luz de Dios y la condición necesitada de los seres humanos que la buscan. Hay sutiles detalles de pintura musical en ciertas palabras como "luz" o "Señor" (saltillo y "fanfarria" inicial). La parte $\mathrm{C}$ tiene resabios modales en la melodía, reforzados con pasajes con movimientos de quintas paralelas entre sopranos y tenores, lo que se asocia con la idea de "música del pasado" que se relaciona con una súplica "existencial", la que se remontaría a los albores de la humanidad.

46 Sin embargo, en los registros fonográficos de esta pieza a los que he accedido, se escuchan introducciones diferentes, sin esta cita.

47 Salas 1965: 100. 
Por su parte, tanto en la Misa a la Chilena como en la Misa de la Cruz del Sur el Señor ten piedad está en modo menor, reforzando el carácter de súplica, mientras que en ambas obras predomina el modo mayor en el Gloria y el Padrenuestro, subrayando el carácter de alabanza y de confianza en la divinidad. Asimismo, en ambas misas el canto de salida es una cueca, subrayando tanto la referencia nacional a Chile como la idea de un impulso alegre para servir a Dios en la vida cotidiana después de participar en la celebración de la misa. A esta remisión a la dimensión nacional me referiré en la siguiente y última sección.

\section{PERSPECTIVAS}

Respecto del interés propiamente "artístico" o "musical" en estas obras, las dos misas "folclóricas ${ }^{48 " ~ r e v i s t e n ~ i m p o r t a n c i a ~ p a r t i c u l a r . ~ C o m o ~ h e ~ d i c h o ~ a n t e r i o r-~}$ mente, en ellas convergen distintas tradiciones musicales y se aprecian recursos armónicos e instrumentales llamativos al servicio de la relación entre música y palabra. No resulta extraño que estas obras, dentro del rubro religioso, sean las más difundidas de Bianchi más allá de Chile ${ }^{49}$ o constituyan, especialmente en el caso de la Misa a la Chilena, antecedentes de varias propuestas que desarrollaría la Nueva Canción Chilena ${ }^{50}$. Sin embargo, piezas orquestales como el Te Deum laudamus y Oh Señor envía tu Espíritu merecerían mayor difusión con un buen registro fonográfico, al igual que La historia de Belén y el resto del repertorio navideño de Bianchi. Aquellas piezas religiosas litúrgicas de menor formato como el Ave María, el Magnificat o A Santa Teresa de los Andes se ajustan bien a criterios funcionales propiamente litúrgicos y al mismo tiempo pueden enriquecer el repertorio de conjuntos vocales y corales.

Se plantea además que más allá de la dimensión musical, hay aspectos teológicos y socioestéticos que se consideran para interpretar el legado religioso de Bianchi. De acuerdo con Stefani (1993), la historia de la música sacra cristiana está atravesada por la tensión teológica entre los conceptos de trascendencia e inmanencia divinas, es decir, el concepto de un Dios personal que está más allá del entendimiento y comprensión de sus criaturas y al mismo tiempo se revela, se acerca a estas y se manifiesta en la experiencia humana. En el ámbito de la Iglesia católica, la concepción trascendente de Dios implica un estilo de música litúrgica cercano al canto gregoriano o al repertorio polifónico religioso tridentino. En cambio, la concepción inmanente de Dios implica estilos cercanos a la música religiosa popular en distintas épocas: los himnos ambrosianos, los laude franciscanos, música de bailes y cofradías religiosos, y en general la música religiosa de raíz folclórica, popular o tradicional posconciliar. Se advierte que la música religiosa de Bianchi, escrita siempre en castellano y concebida para la participación de

48 El término "misas folclóricas" se ha aplicado al caso de las obras de Bianchi y de otros compositores chilenos (Raúl de Ramón, Ángel Parra, Humberto Sagredo) o latinoamericanos (Chabuca Granda, Ariel Ramírez), aunque su uso es muy discutible. Ver Salas 1965 y Guerra 2014.

49 León 2011: 99

50 Guerra 2014. 
varones y de mujeres, presenta según sea el caso distintas convergencias entre la trascendencia (por ej., Magnificat) y la inmanencia (por ej., Canción al Niño Dios), donde una prevalece sobre la otra o donde se logra algún nivel de equilibrio entre ambas (por ej., Misa de la Cruz del Sur).

Por otra parte, a partir de la noción de matrices sociales de identidad que propone Katia Mandoki ${ }^{51}$ en el marco de su teoría estética, el Concilio Vaticano II se puede entender como una reactivación del diálogo e intercambio social entre la matriz religiosa católica y las demás matrices que articulan el tejido social de la cultura occidental. Propuestas musicales posconciliares como la obra de Vicente Bianchi se pueden entender como el resultado del encuentro entre al menos tres matrices: la matriz religiosa católica, la matriz artística (especialmente la matriz artística popular) y la matriz nacional comprendida en pluralidad (matrices nacionales). En este legado, tanto el uso del castellano como sus rasgos propiamente musicales han facilitado el acercamiento entre los creyentes y el rito religioso católico, mientras simultáneamente apelan a expresiones artísticas populares atingentes a su cultura local, reforzando así su adherencia nacional y religiosa. Sin duda estos rasgos fueron reconocidos por autoridades eclesiásticas como el cardenal Silva Henríquez que por esta razón brindó apoyo a la obra de Bianchi, o como el propio compositor ha dicho (a propósito de la Misa a la Chilena, pero aplicable a toda su música religiosa): "Solo he querido contribuir al propósito de la Iglesia de volver al canto comunitario, a la participación del pueblo en la liturgia. Una participación que le permita expresarse en su propio idioma y en su propia música ${ }^{52 " . ~}$

En síntesis, la obra musical religiosa de Vicente Bianchi cumple con requisitos que permitirían considerarla como repertorio canónico, según los criterios de Dahlhaus ${ }^{53}$. Es una obra que ha recibido juicios favorables desde puntos de vista funcional, histórico y estético, y ha adquirido prestigio, apoyo institucional y respaldo de estratos portadores. Esperemos que en futuras investigaciones se profundice más en este legado, cuyo estudio exhaustivo aún está pendiente.

\section{BIBLIOGRAFÍA}

Dalhaus, Carl

1983 Analysis and Value Judgement [Monographs in Musicology, $\mathrm{N}^{\circ}$ 1]. Traducción de Siegmund Levarie. Nueva York: Pendragon Press.

González Rodríguez, Juan Pablo, Óscar Ohlsen Vásouez y Claudio Rolle Cruz 2009 Historia social de la Música Popular en Chile, 1950-1970. Santiago: Ediciones Universidad Católica de Chile.

Guerra Rojas, Cristián

1999 "Tradición, modernidad e hibridaciones: el caso de la Misa a la Chilena de Vicente Bianchi”, Música popular en América Latina. Actas del $2^{\circ}$ Congreso de la IASPM-AL.

\footnotetext{
51 2006a: 76, 2006b: 92.

52 Salas 1965: 100.

53 1983: 10-17.
} 
Editado por Rodrigo Torres Alvarado. Santiago: Fondo Nacional para el Desarrollo Cultural y las Artes (Fondart), pp. 341-356.

2014 "La Nueva Canción Chilena y las misas folclóricas de 1965”, Palimpsestos sonoros: Reflexiones sobre la Nueva Canción Chilena. Editado por Eileen Karmy Bolton y Martín Farías Zúñiga. Santiago: Ceibo, pp. 81-97.

2017 "La Misa Sudamericana de Vicente Bianchi: sudamericanidad e hibridación”, Sonidos de América. Visiones de América. Actas del $12^{\circ}$ Congreso de la IASPM-AL. Editado por Heloísa Duarte Valente y otros. En prensa.

LEón SMith, Silvia

2011 Vicente Bianchi. Músico por mandato divino. Santiago: Sociedad Chilena del Derecho de Autor.

MANDOKI, KATYA

2006a Estética cotidiana y juegos de la cultura. Prosaica 1. Ciudad de México: Siglo Veintiuno.

2006b Prácticas estéticas e identidades sociales. Prosaica 2. Ciudad de México: Siglo Veintiuno.

Salas Viu, Vicente

1965 "Aplicación del folklore a la música religiosa (Foro)", Revista Musical Chilena, XIX/94 (octubre-diciembre), pp. 96-102.

SATTLER JiméneZ, NANCY

2014 "Crónica - Creación musical chilena", Revista Musical Chilena, LXIX/223 (enerojunio), pp. 115-139.

Stefani, Wolfgang Hans Martin

1993 The concept of God and sacred music style: An intercultural exploration of divine transcendence/immanence as a stylistic determinant for worship music with paradigmatic implications for the contemporary Christian context. Tesis doctoral. Michigan: Andrews University.

\section{Entrevistas}

Entrevista a Vicente Bianchi Alarcón. Cristián Guerra Rojas y Álvaro Menanteau Aravena. Santiago, 16 de noviembre de 2016. 